\title{
The Music Skill's Teaching Reform of Preschool Education Major Under the New Situation
}

\author{
Tong-xiang Zheng ${ }^{1}$ \\ ${ }^{1}$ Preschool Education Institute \\ Xuanhua Science\& Technology Vocational College \\ Xuanhua, China
}

\author{
Xiao-fei $\mathbf{L i}^{2}$ \\ ${ }^{2}$ Department of Music and Preschool Education \\ Zhangjiakou University \\ Zhangjiakou, China
}

\begin{abstract}
With the advancement of quality education, preschool music education plays more and more important role, and puts forward a new standard and quality requirement to preschool music teachers. This will inevitably initiate thinking about music teaching model's reform of preschool education major. This paper aims to study the present situation and problem of preschool education major's music skill course, and put forward the corresponding improvements suggestions. It will make the music skill course more in line with the characteristics of preschool education major, and more conductive to promote the students' practical application ability in kindergarten.
\end{abstract}

Keywords: preschool education; music skill; reform

\section{INTRODUCTION}

In recent years, the preschool education specialty becomes popular. The learning quality of preschool education major's students directly affects the construction quality of kindergarten teacher team, and has important effect to preschool education personnel training. From the training objectives of preschool education major, we can see that the preschool teachers must develop morally, intellectually, physically and aesthetically, have professional knowledge ability, and can play some skills skillfully, such as singing, dancing, painting and writing. The music education, especially the music skill teaching, has a very strong practical significance in improving students' practical ability ${ }^{[1]}$.

Preschool teachers' music skill refer to that, in preschool music education work, teachers should have the music accomplishment and education skills to match the requirement of education target and the particularity of education object's age. The preschool music teaching activity is one of the important indexes of assessing teachers' teaching ability. It has a very important practical significance of how to carry out the collective music activities effectively, and promote the harmonious of young children. The breach to solve this problem is to strengthen teachers' music skills ${ }^{[2]}$. However, in the music skill course's teaching process, many colleges and universities continue to refer or use the traditional teaching model of undergraduate music universities. It can't reflect the talent cultivation characteristics, applied and technical. And it also ignores to cultivate the students to carry on the jobs required skills. In this case, the students lack interest in learning, teaching also in the bottleneck of learning skills and methods, and class can't work for the practical use ${ }^{[3]}$.

2. Music skills course's characteristics and requirements of preschool education major

\subsection{Course's characteristics}

The set of vocational skills accords to the principle of "actual, practical and practice". In the music skill course, the theme is improving skills, and the subject is combining closely with the kindergarten. And the main courses are playing the piano, vocal music, dance, etc. the characteristics of these courses can be summarized as the following points.

(1) Practice

The acquisition and improvement of music need to be repeated with the process of practice, skilled, correct and completion, which is gradually perfected in the process of nurture learning. Music skill practice teaching should choose the students' practice as the subject under a learning-by-doing environment. At this point, the teachers should pay attention to guide students to apply theoretical knowledge to actual in particular, transforming into professional ability.

\section{(2) Pertinence}

Pertinence means that, for the employment post, preschool teachers need to have the basic skills of playing, dancing, and singing, and the corresponding skills courses should be opened. Of course, employment post is a post group of certain commonality. It involves skills that one single course can't cover, and need the corresponding teaching method, such as the integrated skills of playing, 
singing and dancing.

(3) Occupational

Professional skill appraisal assessment is the professional career requirements for practitioners, and the examinee should have the necessary theoretical knowledge, basic skill, and a certain comprehensive ability to solve the actual problem. Music skill course teaching combined with the kindergarten teachers' professional qualification standards and professional skill appraisal requirements. It promotes students to strengthen vocational skills training by obtaining skill certificate. Music skill appraisal test are piano, vocal music, dancing, music theory, sightsinging practice ear, impromptu accompaniment distinction, etc. Colleges can reference directly demonstrated skill appraisal exam outline and teaching material to make the teaching plan, and combine with the characteristics of preschool education major to set skill operation module.

\subsection{The requirement of preschool music education major skills}

\section{(1) Accurate fluency}

Accuracy means less mistakes and errors, and finish smoothly rather than intermittent or interval. Such as piano playing, a knot or pause "break phenomenon", will interrupt the player's music thinking and impact the integrity, even can't continue, and the organization of classroom teaching will be discounted.

(2) Music performing

The master of music skills should pursue and achieve the artistic effect of "the remarkableness for voice, expression and shape". After course learning and training, students should have good art sense, namely aesthetic consciousness. Such as vocal music performance, student should not only have a beautiful song, but also have the combination of singing, performance and shape, getting perfect experience.

(3) Environmental adaptability

In the preschool teaching, the teachers often need to accompany the music works or the plait. It requires the students to strengthen music comprehension and the rapid response ability, directly affecting the music activities effect as well as the development of literature and art activities.

\section{Problems in the preschool education major music skill teaching}

\subsection{The orientation problem of talent training goal}

In Chinese preschool education major, the orientation of talent training goal is more and more ambiguity, especially for music skills knowledge, ability and quality, leading to the music skill ability of preschool teachers trained in the school deviate from preschool teacher's professional standards seriously, and can't meet the demand of high quality music synthesis skill talented person in kindergarten, mainly reflected in two aspects:
(1) Music skill training goal and specification orientation is not clear

The talent training goal orientation of preschool education major, prefer the students' basic knowledge of culture, existing the goal and specification orientation problem of "Heavy knowledge and light skills, heavy theory and light practice". The expression of music skill is also not specific, such as knowledge skills of education activity and aesthetic ability management

(2) Graduate job orientation fails to reflect the post's continuity

Graduate job orientation reflects the positioning of preschool education student initial position, ignoring the development of students' career development, the obtainment of re-employment service, which is not unfavorable to construct lifelong education system. Music skill training can't only understand as teaching children to sing songs, play the harp, and listen to music, but also should to help students to find pre-service music skills learning rule, so that the students can be qualified to the initial post teaching work, and finish the four important activities alone, which are letting the children sing, acting with music, percussion music and music appreciation.

\subsection{The set-up problem of music skill course}

The music skill courses of preschool education major include four courses, which are piano, singing, music theory and sightsinging practice ear, and children's impromptu accompaniment. The setup of these four courses reflects subject-centered design. The independence and closeness of subject cause that it is hard to link up theoretical knowledge and practical skills very good. It is not suitable for applied talents to form skill learning rule and autonomous learning habit.

\subsection{The problem of music skills teaching outline}

Music skills courses include four courses, which are piano, singing, music theory and sightsinging practice ear, and impromptu accompaniment four basic courses. Preschool students must be skilled in these four basic courses, which occupy very important position and role in the whole course structure of preschool education major. But, there are some problems in the music skills teaching outline.

(1) The expression of course nature is lack of serious scrutiny.

(2) The course objective reflects the rigid requirements, which is not conductive to the students' comprehensive development.

(3) Expression of course content and requirement lays particular stress on teachers" "tutorial" rather than the students" "learning process".

It has important significance to music skills that analyzing the nature of each music skill course carefully, positioning objective accurately, and formulating course content and requirements reflecting the combination of tutorial and learning process. 


\subsection{Problems on the teaching implementation of music skills}

With the expansion of the preschool education resources in China, the employment status of preschool education graduates is very considerable, leading to many students choose the preschool education major. Since there is a serious shortage of teaching staff in preschool education, the number of teachers and students are not in direct proportion, which affects the quality of talent seriously.

With the fast development of preschool education and the weak foundation of students, old teaching material can't match the actual demand of the kindergarten music teaching activities. And the college can't introduce the forefront relevant knowledge and teaching contents' new method and new means timely, which is inconvenient for learners' self-improvement.

\subsection{The problem of teaching evaluation}

Teaching evaluation is a kind of effective control measure to make the teaching process to achieve the teaching goal. Teaching evaluation includes the evaluation of both the teaching and learning.

At present, the teaching evaluation mainly includes teaching inspection section's evaluation and students' evaluation, lack of the evaluation of peer teachers, and graduates' music skills, experts in this field, and so on.

The learning evaluation mainly adopts the teachers' evaluation. But this unified teaching evaluation may damage the developing students' comprehensive, integrity and richness.

\section{Teaching reform proposals of preschool education major}

\subsection{Clear positioning of talents training goal}

Personnel training objectives of preschool education major should be clear positioned, so as the professional quality and cultural accomplishment, the children education theory knowledge and professional skills that should be grasped, and the comprehensive quality that in urgent need, such as "good professional ethics+ playing, dancing, singing+ advanced teaching method+ the kindergarten education activity design ability", etc. Then the students of preschool education major will have complex skills when graduation, and be more flexible in the field of preschool education.

\subsection{Strengthen the professional teacher staff of music skill}

The teachers overall strength of preschool education major is still weak in China, and need innovation reforms to further strengthen. The preschool teachers' music skills are lower, and the prominent reason is that the students' number of preschool education major is too much, but the teachers' is serious deficiency. The college should balance the number of teachers and students, improve the quality of students, and strengthen teachers' music skills, improving the teaching ability.

\subsection{Add teaching content and teaching facilities with epochal character}

The preschool education major's teachers not only have to grasp the fitness of teaching contents, but also have to go to the kindergarten painstakingly to observe the children's situation, such as what kind of understanding dose the children have to the music, what's their body expression, and so on. Without life we can't create good artistic work. In the same way, without young children, the music skill course can't develop for a long time. For example, the famous western music education system, Orff music teaching method, is in constant practice, and put forward the importance of "rhythm" to children, which is our learning model.

In the aspect of teaching equipment, piano room and dance room should also be built up. Especially in the arrangement of the classroom, it should give the students a sense of relax and comfortable, so as to make students to learn music, dance, and knowledge in an open and free environment.

Teaching tools should also be considered. In the ordinary teaching, the hammer, angle iron, sand, double-barrelled cylinder, tambourine, etc can be used, which are commonly used in kindergarten. The students may also make free creation, and distinguish different timbre of liquidity. Real knowledge comes from practice, so as the art.

\subsection{Build diversified teaching evaluation system}

The original music skills evaluation gives priority to term exams, which focus on the result and is a single way. We should change this way and put an emphasis on students' process evaluation and development evaluation. Students' process evaluation and development evaluation is a try to establish the diversified evaluation system of preschool education major, which is not very mature now. But from the effect of model colleges, we can see that their implementation basically achieved the diversification of evaluation methods. In the past, the students are only evaluated from colleges and teachers when assigned. Now we should increase the evaluation from students themselves, the kindergarten teachers, and parents of children. This evaluation system is multi-azimuth and multi-angel, and can guarantee to quality of preschool education major graduates more effectively.

\section{Conclusion}

Preschool teachers are typical interdisciplinary talents. In the process of preschool teachers' cultivation, we must seize the key. The students not only need solid basic skills, but also have to achieve mastery through comprehensive study, enhance professional ability in practice, then become a qualified inter-disciplinary talent that can meet the 
demand of preschool education industry development. Based on the analysis of music skill course's teaching problems, this paper put forward the corresponding improvement suggestions, hoping that preschool education major graduates can accord with the times development and preschool music education's requirement.

\section{References}

[1] Li Ping. Preschool education major music skills course and its present condition analysis of Jiangxi science and technology normal university. Music space time,2013,14:107.

[2] Luan Ju. Reform analysis of preschool education major's music skills course in higher vocational colleges. Cultural and educational materials, 2012 (31) : 81-82.
[3] Zhou Dongen. The teaching reform of preschool education major music skills courses in higher vocational colleges. Journal of Liaoning vocational college, 2010, 12 (10) : 79-81.

[4] Liu Xiao. The music teaching reform's practice and exploration of preschool education major under the new situation. Journal of popular culture: academic, 2013 (21) : 286-287.

[5] Liu Bing. Teaching thinking of preschool education major music basic skills. Journal of contemporary education practice and teaching research (electronic version), 2015 (1) : 107-107.

[6] Wang Yao. Taking about the music skills teaching of preschool education major from the perspective of music aesthetic psychologist elements. Journal of arts education, 2008, 11:031. 